\title{
Quantitative Rheological Indicators for Soil Physical Degradation
}

\author{
${ }^{1}$ T. SZEGI, ${ }^{2}$ E. TOMBÁCZ, ${ }^{2}$ ZS. CZIBULYA, ${ }^{3}$ J. AKAGI \\ and ${ }^{3} \mathrm{~A}$. ZSOLNAY \\ ${ }^{1}$ Szent István University, Department of Soil Science and Agrochemistry, Gödöllő, \\ ${ }^{2}$ University of Szeged, Szeged (Hungary) and \\ ${ }^{3} \mathrm{GSF}$, Institut für Bodenökologie, München (Germany)
}

\section{Introduction}

Most of the fertile soils have been under cultivation for centuries. Unfortunately, almost the entire area has experienced erosion and/or structural degradation mainly due to inappropriate land use and practice all over the world.

Soil samples were taken from a topographical/erosion catena in Hungary and an experimentally set up desertification site in Germany to study relationships among rheological parameters and other soil properties related to tolerating deformation and shear forces, and to determine quantitative physical indicators relevant to the structural state of the soil matrix for predicting soil degradation.

\section{Materials and Methods}

\section{Description of the study sites}

Location 1: Puch, Bavaria, Germany (D-PUCH). - The three treatments are as follows: agricultural plot (A); "green fallow" (G) and "black fallow" (B).

The " $A$ " plot is a field under normal cultivation with crop rotation and fertilization. The "G" plot has been ploughed twice yearly over 50 years. In the remaining time vegetation has been allowed to grow without any control or fertilization. Plot " $\mathrm{B}$ " - an extreme case of mismanagement - is unfertilized and has been ploughed over 50 years whenever vegetation appeared. As a result there are no input residues from plants and the soil's organic matter is constantly exposed to aeration.

Location 2: Szent István University, experimental farm, Hungary (H-GODO). The soils of the farm located on the „North Plain Alluvial Fan” (a small geographical area of the "North Hungarian Mountains") developed mainly on Pleistocene calcareous loess, with different histories of erosion and structural degradation. Three profiles with different extent of erosion and compaction were chosen on the

Correspondence to: TAMÁS SZEGI, Szent István University, Department of Soil Science and Agrochemistry, H-2103 Gödöllö, Páter Károly út 1. Hungary. E-mail: szegi.tamas@ mkk.szie.hu 
slope of a catena for the investigation. The first profile, named "Low Erosion" profile (LE) - situated on the upper third part of the slope - is characterized by moderate erosion and strong compaction. The second, the "High Erosion" profile (HE) is located in the middle of the hill. The profile is strongly truncated, and no marks of compaction are observable. The third, the "Cumulic" profile (CV) is found at the bottom of the slope.

\section{Laboratory methods}

Air-dried soil samples were ground to pass a $2 \mathrm{~mm}$ sieve before chemical analysis. Soil organic matter (SOM) content was measured after removing the organic light fraction by the Walkly and Black procedure (NELSON \& SOMMERS, 1982). The cation exchange capacity of bulk soil samples was measured by the modified Mehlich method $\left(\mathrm{BaCl}_{2}\right)$ (BuZÁs, 1988). Particle size distribution was determined by the pipette method and the $\mathrm{CaCO}_{3}$ content by the Scheibler volumetric method (BUZÁs, 1988).

The Sekera-method was carried out for simple aggregate stability measurement. Aggregates of 1-3 mm size were placed in Petri dishes and $10 \mathrm{ml}$ of distilled water was added. Aggregate stability was estimated based on the dispersion of aggregates after 10 minutes (BUZÁs, 1988).

pF-Water holding capacity was measured at different tensions $(-0.3$ and -15 bars), which indicates water holding capacity at $\mathrm{pF} 2.5$ (field capacity) and $\mathrm{pF} 4.2$ (wilting point). The available water content was calculated by subtracting the water content at wilting point from the water content at field capacity (BUZÁs, 1988).

Simple water holding capacity was measured on $100 \mathrm{~g}$ uncrushed air-dried soil sample. Distilled water $(100 \mathrm{ml})$ was filtered through the sample and the percentage of moisture was determined 1 hour after no dripping.

Rheological measurements. - In the course of preparing soil suspensions for rheological measurements the suspension concentration is the most important step. The equilibrium sediment approach was selected for getting comparable data, which are characteristic of the given particle network formed spontaneously in different soils. The suspension concentration in equilibrium sediment formed after a long standing can be considered as the lower limit of particle content in the particle network extended over the whole volume. Soil suspensions were left for a week to form sediments, then the excess water above the sediment was removed and the humidity of equilibrium sediments was measured. This water content - proportional to the water holding capacity of soils - can be considered as a respective state of soil suspensions in the comparison of different samples. Soil pastes with the characteristic humidity were prepared with individual weighing of solid and distilled water, then mixing them thoroughly. Before rheological measurement, soil suspensions were stored in closed plastic containers for a day to reach equilibrium in wetting, swelling and structural state.

The rheological measurements were performed with a stress controlled HAAKE RS 150 rheometer using vane (FL20) and plate-plate sensor (PP20 Ti) at $25 \pm 0.1{ }^{\circ} \mathrm{C}$ temperature, controlled by a HAAKE DC 30/K20 thermostat. The vane rotor placed 
approximately in the centre of the sample volume was rotated at a constant (very low) velocity and the resulting shear stress was recorded in time. After a linear part of torque-time response due to the stretching of the network bonds interconnecting the structural elements (particles or aggregates or both) a maximum was measured. The maximum shear stress can be identified as the yield value above which the network bonds start to break (DZUY \& BOGER, 1983). The yield values were calculated with the RheoWin software.

The flow curve (upward) was determined with a shear rate ramp over 2 minutes from 0 to $10 \mathrm{l} / \mathrm{s}$, and then the ramp was reversed to measure the downward flow curve. The evaluation of flow curves was performed with the RheoWin software, so the maximum of the upward curve, the extrapolated yield value and plastic viscosity of the downward curve according to the Bingham model were determined. The area between the upward and downward curves was also calculated as the measure for thixotropy, using the data analysis option of the apparatus (BARNES et al., 1989; FIRTH \& HUNTER, 1976).

Based on relevant literature the following rheological parameters of suspensions can be determined:

- The absolute yield value is the maximum of shear stress vs the time function from vane measurement.

- The initial shear stress is obtained from the initial maxima of flow curves measured in the direction of increasing shear rate (upward.

- The area of thixotropic loop between the up- and downward flow curves measured over an arbitrary shear rate range (here in low shear region from 0.1 to 10 $1 / \mathrm{s})$.

- The yield value (Bingham) is extrapolated from the linear part of flow curve (downward).

- The plastic viscosity for pseudoplastic suspensions is the slope of the linear part of downward flow curve (Bingham model).

These rheological parameters are related to the particle adhesion, the sensitivity to mechanical effects, and the strength of the physical network built up from particles in soil suspensions.

\section{Results and Discussion}

The results of the analytical data of the samples collected from the ploughed layers (Ap, $0-30 \mathrm{~cm})$ of the treatments of Location 1 (Puch, Germany) (D-PUCH) and profiles of Location 2 (Gödöllö, Hungary) (H-GODO) - given in Table $1-$ show great differences in accordance with the treatments and positions on the slope.

Soil samples originating from Location 1 (D-Puch) contain $\mathrm{CaCO}_{3}$, but their soil organic matter content is very low and decreases with the number of cultivations and de-vegetation. These properties influence other soil parameters, like $\mathrm{pH}, \mathrm{CEC}$ etc. Samples from Location 2 (H-GODO) lack $\mathrm{CaCO}_{3}$, their soil organic matter content, however, is relatively high, and a good tendency can be observed in soil organic matter according to the profile's location on the slope. The soil organic 
Table 1

Analytical data of soil samples collected from the ploughed layers (Ap, 0-30 cm) of the treatments of Location 1 (Puch, Germany) (D-PUCH) and profiles of Location 2

(Gödöllö, Hungary) (H-GODO)

\begin{tabular}{|c|c|c|c|c|c|c|c|c|c|}
\hline $\begin{array}{l}\text { Treatments } \\
\text { and profiles }\end{array}$ & $\begin{array}{c}\mathrm{pH} \\
\left(\mathrm{H}_{2} \mathrm{O}\right)\end{array}$ & $\begin{array}{c}\mathrm{SOM} \\
\% \\
\end{array}$ & $\begin{array}{c}\mathrm{CaCO}_{3} \\
\% \\
\end{array}$ & $\begin{array}{c}\mathrm{CEC} \\
\mathrm{cmol} / \mathrm{kg}\end{array}$ & $\begin{array}{l}\mathrm{B} \\
\%\end{array}$ & $\begin{array}{c}\text { Sand } \\
\% \\
\end{array}$ & $\begin{array}{c}\text { Clay } \\
\%\end{array}$ & $\begin{array}{c}\text { Texture } \\
\text { FAO }\end{array}$ & $\begin{array}{c}\mathrm{BD} \\
\mathrm{g} \cdot \mathrm{cm}^{-3}\end{array}$ \\
\hline \multicolumn{10}{|c|}{ Location 1 (D-PUCH) } \\
\hline A: Agric. plot & 6.63 & 0.9 & 3 & 25 & 98 & 68.3 & 17.2 & SL & 1.4 \\
\hline G: Green fallow & 7.07 & 0.6 & 3 & 23 & 98 & 63.9 & 23 & $\mathrm{~L}$ & 1.5 \\
\hline B: Black fallow & 7.10 & 0.6 & 2 & 20 & 92 & 63 & 23.9 & $\mathrm{~L}$ & 1.6 \\
\hline \multicolumn{10}{|c|}{ Location 2 (H-GODO) } \\
\hline LE: Low erosion & 6.1 & 1.5 & 0 & 28 & 55 & 34 & 32 & $\mathrm{CL}$ & 1.5 \\
\hline HE: high erosion & 6.1 & 0.5 & 12 & 24 & 55 & 33 & 36.4 & $\mathrm{CL}$ & 1.3 \\
\hline CV: Cumulic & 7.6 & 2.5 & 2 & 40 & 95 & 16.8 & 30.9 & $\mathrm{SiCL}$ & 1.2 \\
\hline
\end{tabular}

Remarks: SOM: Soil organic matter content, \%; CEC: cation exchange capacity, cmol/kg;

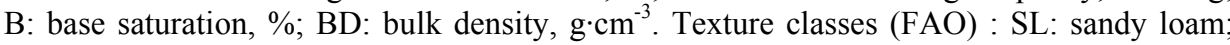
L: loam; CL: clay loam; SiCL: silicate clay loam

matter content of the "Highly eroded" (HE) profile is the lowest, because of quasicontinuous runoff, while that of the profile at the bottom of the slope (CV) is the highest, as it received the eroded topsoil rich in organic material.

Table 2 presents the results of "simple" soil physical parameters together with yield values. In the case of the D-PUCH samples (treatments of Location 1) it is obvious that the best parameters belong to those taken from the normal agricultural field ("A"), and the worst values characterize the bare surfaced samples ("B"). In

Table 2

Physical soil parameters of the soil samples collected from the treatments of Location 1 (Puch, Germany) and profiles of Location 2 (Gödöllő, Hungary)

\begin{tabular}{|c|c|c|c|c|c|c|c|c|c|c|}
\hline \multirow[t]{2}{*}{$\begin{array}{l}\text { Physical } \\
\text { parameter }\end{array}$} & \multicolumn{5}{|c|}{$\begin{array}{c}\text { Treatments of Location } 1 \\
\text { (D-PUCH) } \\
\text { (Puch, Bavaria, Germany) }\end{array}$} & \multicolumn{5}{|c|}{$\begin{array}{c}\text { Profiles of Location } 2 \\
\text { (H-GODO) } \\
\text { (Gödöllö, Hungary) }\end{array}$} \\
\hline & "A" & & "G" & & "B" & CV & & LE & & $\mathrm{HE}$ \\
\hline $\mathrm{pF} 2.5 \%$ & 38 & $>$ & 36 & $>$ & 32 & 40 & $>$ & 32 & $>$ & 31 \\
\hline Simple Wk \% & 72 & $>$ & 68 & $>$ & 65 & 82 & $>$ & 75 & $>$ & 66 \\
\hline $\begin{array}{l}\text { Aggregate } \\
\text { stability (S) }\end{array}$ & best & $>$ & medium & $>$ & poor & best & $>$ & medium & $>$ & poor \\
\hline $\begin{array}{l}\text { Rheology } \\
\text { (Yield value) } \\
\mathrm{Pa}\end{array}$ & 311 & $>$ & 171 & $>$ & 74 & 208 & $>$ & 158 & $>$ & 140 \\
\hline
\end{tabular}

Remarks: $\mathrm{pF} 2.5 \%$ : water content at $\mathrm{pF} 2.5$; Simple Wk \%: water holding capacity; Treatments: A: agricultural plot; G: green fallow; B: black fallow. Profiles: CV: cumulic profile; LE: low erosion; HE: high erosion 
addition to continuous physical disturbance (cultivation), the breakdown of the binding agents between soil particles, and the soil conserving effect of vegetation are missing. All these result in poor physical properties (aggregate stability, water holding capacity, moisture content).

The same tendency can be observed for the H-GODO samples (profiles of Location 2). The "Cumulic profile" (CV) has the best, while the strongly eroded profile (HE) is characterized by the worst properties, because of the continuous downward mass movement on the slope, which breaks down and/or washes down the binding agents, just like cultivation.

A

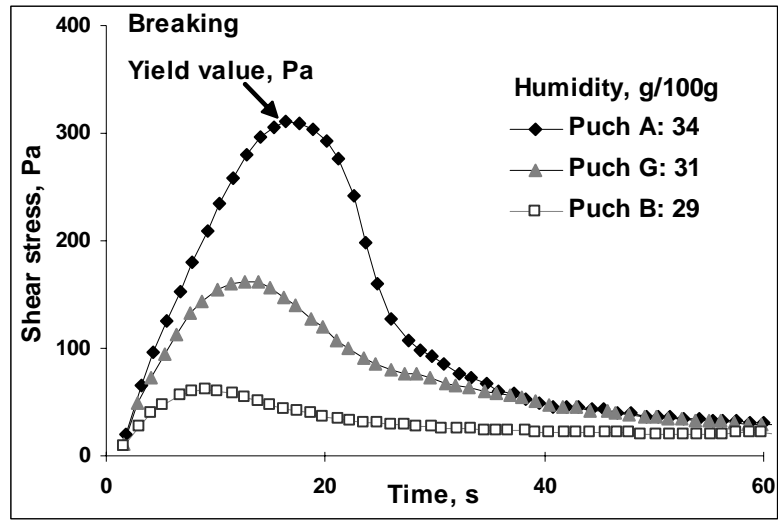

B

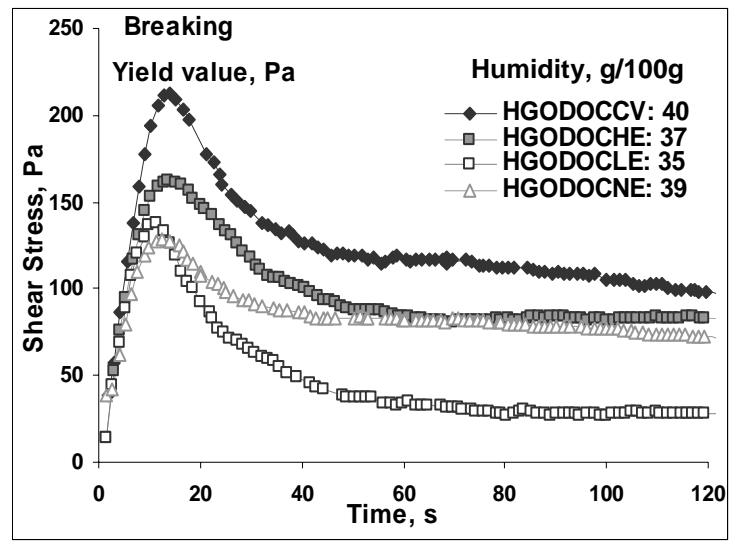

Fig. 1

Shear strength curves of the soil samples collected from the treatments Location 1 (Puch, Germany, D-PUCH) (A) and profiles of Location 2 (Gödöllö, Hungary, H-GODO) (B), measured by the vane method. Treatments: A: agricultural plot; G: green fallow; B: black fallow. Profiles: CV: Cumulic; HE: high erosion, LE: low erosion 
The results of the absolute yield value shear strength of the particle network, measured by the vane method in soil samples from Location 1 (D-PUCH) and Location 2 (H-GODO) are given in Figs. 1A and 1B. The curves maxima represent the highest shear stress tolerable by the soil particle network.

The maxima (the absolute yield values) of shear stress vs. time curves (Fig. 1) significantly differ for the samples. This is especially true for the samples originating from Location 1 (D-PUCH) (Fig. 1A). A much stronger, shear tolerant particle network was built up in the soil under normal cultivation (" $A$ " treatment) than in the mismanaged field ("G"), while only a fragile structure formed in the black fallow ("B" treatment), where all plants were usually removed from the soil during the long experimental period.

A

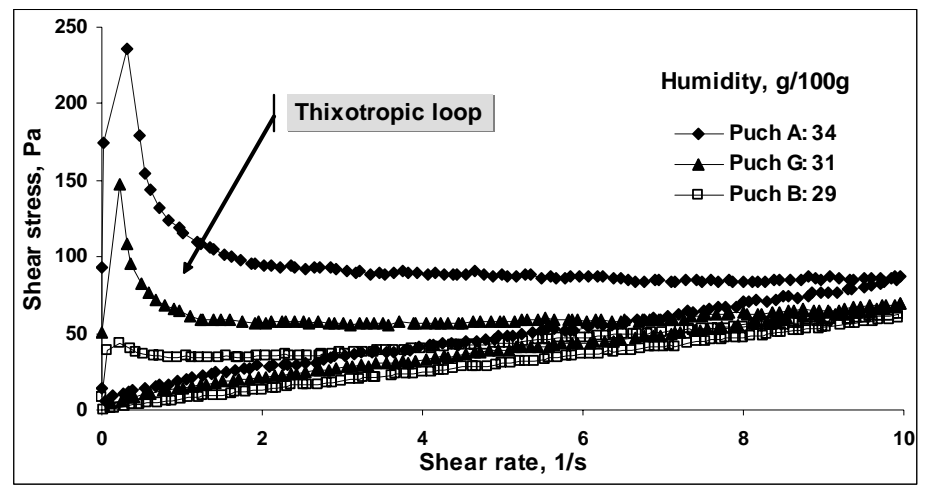

B

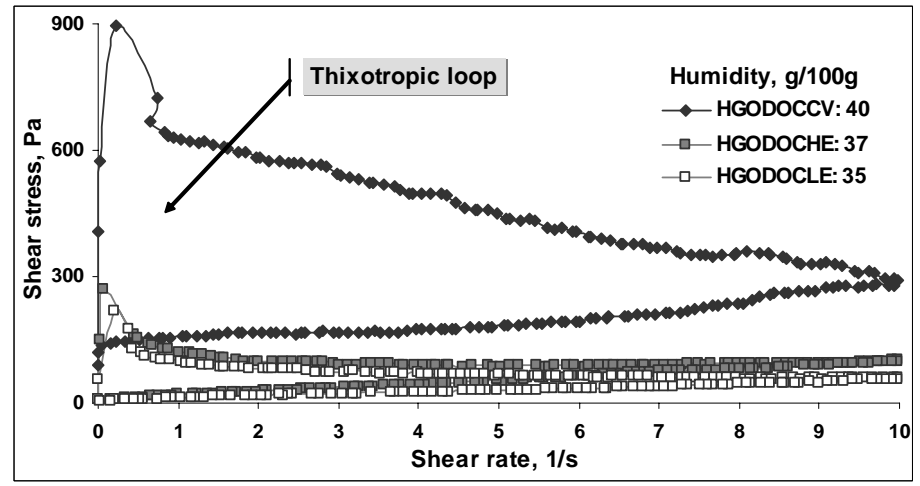

Fig. 2

Flow curves obtained from up- and downward shear rate ramp measurements for concentrated suspensions of samples originating from the treatments of Location 1 (D-PUCH) (A) and profiles of Location 2 (H-GODO) (B). Treatments: A: agricultural plot; G: green fallow; B: black fallow. Profiles: CV: Cumulic; HE: high erosion, LE: low erosion 
Differences among the yield values of the samples from Location 2 (H-GODO) (Fig. 1B) from the erosion catena are slighter, and no clear trend in shear tolerance was observed, as the structure of the highly eroded sample (HE) is stronger (possibly due to the higher $\mathrm{CaCO}_{3}$ content) than that of the low erosion sample (LE). This phenomenon suggests that inorganic binding agents (mostly $\mathrm{Ca}^{2+}$ ) can build up a stronger (not so vulnerable) structure than soil organic matter.

The results of shear tolerance of the particle network, flow curve measurements to determine initial shear stress, thixotropy and plastic flow behaviours are given in Figs. 2A and 2B for samples collected at Location 1 (D-PUCH) and Location $2(\mathrm{H}-$ GODO), respectively. In order to get structural characterization relevant to the natural condition (e.g. downward mass movement) and agricultural practice (e.g. tillage), the flow behaviour of soil suspensions was measured in the low shear rate range. The general features of the flow curves Figs. 2A and 2B are typical for moderately adhesive systems, which are sensitive to deformation (BARNES et al., 1989). The initial maxima of flow curves represent the highest shear stress that the soil particle network can tolerate. This value shows good correlation with the breakpoint (the absolute yield value) of the shear strength curves (Figs. 1A and 1B). The strength of the particle network formed during a one day standstill is characterized by the area of the thixotropic loop between the up- and downward curves.

The flow curves of samples from Location 1 (D-PUCH) (Fig. 2A) differ greatly, similarly to the results of shear strength measurements. The initial maximum on the upward curve of sample "A" showed high yield stress, which suggests that the strength between particles could tolerate the shear at low shear rates. The bonds between the particles, however, seem to break suddenly at higher shear rates and practically no recovery of the particle network occurs during the measurement.

While the difference between the flow curves of the samples from Location 1 (D-PUCH) was systematic, almost the same flow characters were measured in the case of the samples originating from Location 2 (H-GODO (Fig. 2B), with the exception of the $\mathrm{CV}$ sample collected from the accumulation zone of the erosion slope. This latter proves to have excellent structure with high shear resistance (large initial shear stress) and good thixotropy (huge thixotropic loop), which is characteristic of multi-points, relatively strong bonds formed between soil particles during a long standstill.

For the comparison of the measured rheological parameters - related to particle adhesion, the sensitivity to mechanical effects, and the strength of the physical network built up from particles in soil suspensions - the characteristic data were plotted in Fig. 3.

It can be concluded that these parameters change in parallel. Therefore, it seems to be sufficient to define one parameter as indicator for the structural degradation of soil for comparing soil samples in the future. 

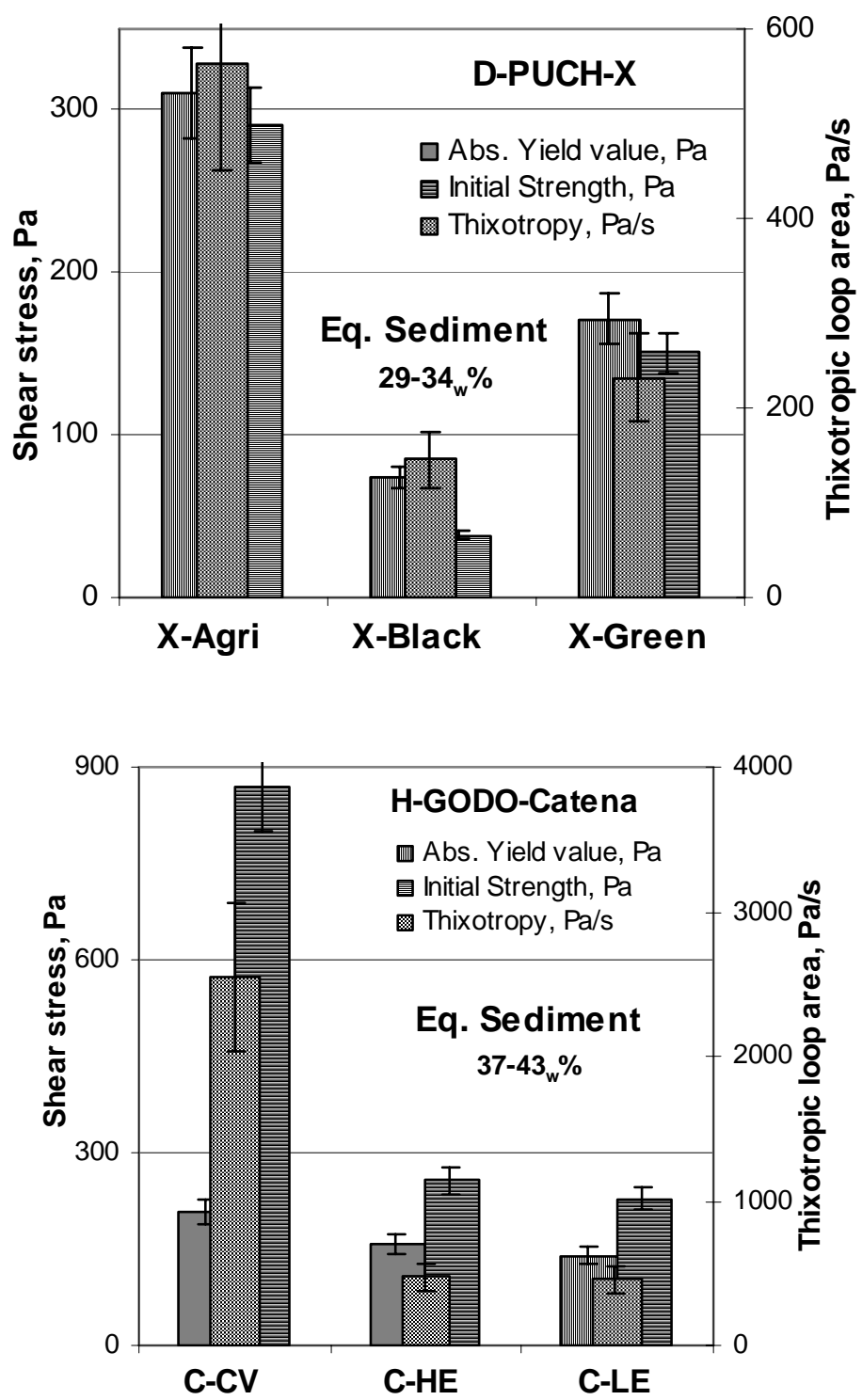

Fig. 3

Comparison of the rheological parameters (absolute yield value, initial strength, thixotropy) of soil samples originating from treatments of Location 1 (Puch, Germany, D-PUCH) and profiles of Location 2 (Gödöllö, Hungary, H-GODO) Treatments and profiles: See Fig. 2 


\section{Conclusions}

Rheology proved to be a useful tool for detecting and quantifying changes due to degradation in microaggregate stability. A strong relationship was established between the strength of aggregation and the natural and agronomic soil parameters related to land use practices. The structure of soil develops in the gradual aggregation of soil particles, in which the organic matter and calcium carbonate content of soil play dominant roles. Under favourable soil conditions (low shear range) the colloidal parameters govern the rheological behaviour. Any change, even a slight one in the organic coating of soil particles or in the composition of the soil solution becomes detectable in the rheological parameters (TOMBÁCZ et al., 2004). Suspensions have to be comparable, however, in respect of their mineral composition and concentration. The rheological parameters of soil suspensions in respective state with self-assembled water content changed significantly with their structural and erosion conditions.

In the field with appropriate management in Location 1 ("A" treatment, D$\mathrm{PUCH}$ ) a stronger and more shear tolerant soil structure formed, while overcultivated ("G") or de-vegetated ("B") soils showed significant degradation, which can be quantified with the rheological parameters.

In the case of Location 2 (H-GODO) aggregation was the best in the accumulation profile $(\mathrm{CV})$, most probably because of the lesser disturbance and high biological activity. The cultivated, eroded and structurally degraded soils and their related parameters showed strong relationship with the rheological values as well.

Based on the gained results it can be concluded that rheological parameters respond sensitively to degradation processes, so they can be considered as promising tools for the early detection and prediction of soil degradation processes.

\section{Summary}

A lot of attention is being paid to the understanding of the influence of soil degradation on human life at the beginning of the $21^{\text {st }}$ century. Among the many types of degradation processes, structural degradation is widespread on huge areas in Europe. For better control, it is needed to get familiar with all the driving forces, the main reasons that lead to soil degradation (VÁRALLYAY, 2003; ESB, 2002). In addition to unfavourable natural conditions, inappropriate land use has an important impact on micro-aggregate stability and the rate of tolerance to deformation forces, such as cultivation and erosion.

Rheological measurements provide new quantitative information on particleparticle interaction, the colloidal stability and structure of concentrated suspensions in general. Field samples from loess derived agricultural soils were investigated. In addition to general laboratory analyses (soil organic matter content, $\mathrm{CaCO}_{3}$ content, CEC), conventional, simple aggregate stability, and water retention measurements and rheology were applied for investigating the micro-aggregate stability of the samples. The evaluation of pseudoplastic flow curves indicated close relationships 
between the strength and stability of the physical network and the composition of the suspensions. These soil properties have strong, well-defined connection with tolerating cultivation and capability for erosion.

The present work was supported by the EC (GOCE-CT-2003-5054541).

Key words: micro-aggregate stability, land use, rheology, cohesive structure, shear tolerance

\section{References}

Barnes, H. A., Hutton, J. F. \& Walters, K., 1989. An Introduction to Rheology. Elsevier. Amsterdam.

BuZÁs, I. (Ed.), 1988. Manual of Soil and Agrochemical Analysis. II. Physico-chemical and Chemical Methods of Soil Analysis. (In Hungarian) Mezőgazda Kiadó. Budapest.

DZUY, N. Q. \& BOGER, D. V., 1983. Yield stress measurement for concentrated suspensions, J. Rheology. 27. (4) 321-349.

European Soil Bureau, (ESB), 2002. Soil Thematic Strategy. ESB Research Reports. JRC. Ispra.

FIRTH, B. A. \& HUNTER, R. J., 1976. Flow properties of coagulated colloidal suspensions I., II, III. J. Colloid Interface Sci. 57. 248-275.

Nelson, D. W. \& Sommers, L. E., 1982. Total carbon, organic carbon, and organic matter. In: Methods of Soil Analysis. Part 2. Chemical and Microbiological Properties. (Eds.: PAGE, A. L., Miller, R. H. \& KeEneY, D. R.) $2^{\text {nd }}$ ed. 539-579. ASA, SSSA. Madison, USA.

TomBÁcz, E. et al., 2004 The role of reactive surface sites and complexation by humic acids in the interaction of clay mineral and iron oxide particles. Org. Geochem. 35. 257-267.

VÁRALLYAY, GY., 2003. Role of soil multifunctionality in future sustainable agricultural development. Acta Agron. Hung. 51. (1) 109-124. 